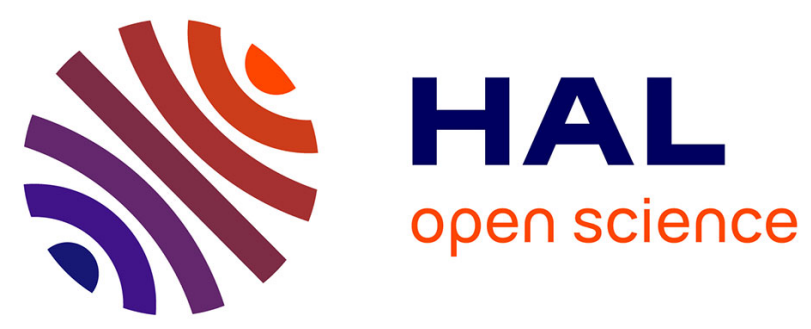

\title{
Concentrations and fingerprints of PAHs and PCBs adsorbed onto marine plastic debris from the Indonesian Cilacap coast and theNorth Atlantic gyre
}

R. Bouhroum, A. Boulkamh, L. Asia, S. Lebarillier, Alexandra ter Halle, A. Syakti, P. Doumenq, L. Malleret, P. Wong-Wah-Chung

\section{To cite this version:}

R. Bouhroum, A. Boulkamh, L. Asia, S. Lebarillier, Alexandra ter Halle, et al.. Concentrations and fingerprints of PAHs and PCBs adsorbed onto marine plastic debris from the Indonesian Cilacap coast and theNorth Atlantic gyre. Regional Studies in Marine Science, 2019, 29, pp.100611. 10.1016/j.rsma.2019.100611 . hal-02194342

\section{HAL Id: hal-02194342 \\ https://hal.science/hal-02194342}

Submitted on 14 Feb 2020

HAL is a multi-disciplinary open access archive for the deposit and dissemination of scientific research documents, whether they are published or not. The documents may come from teaching and research institutions in France or abroad, or from public or private research centers.
L'archive ouverte pluridisciplinaire HAL, est destinée au dépôt et à la diffusion de documents scientifiques de niveau recherche, publiés ou non, émanant des établissements d'enseignement et de recherche français ou étrangers, des laboratoires publics ou privés. 
Concentrations and fingerprints of PAHs and PCBs adsorbed onto marine plastic debris from the Indonesian Cilacap coast and the North Atlantic gyre

BOUHROUM R. ${ }^{1}$, BOULKAMH A. ${ }^{1}$, ASIA L ${ }^{2}$, LEBARILLIER S. ${ }^{2}$, TER HALLE A. ${ }^{3}$, SYAKTI

A.D..$^{4,5}$, DOUMENQ P. ${ }^{2}$, MALLERET L. ${ }^{2}$, WONG-WAH-CHUNG P. ${ }^{2 *}$

${ }^{1}$ Laboratoire des Techniques Innovantes de Préservation de l'Environnement, Université Frères Mentouri, Constantine 1, Algérie

${ }^{2}$ Aix Marseille Univ, CNRS, LCE, Marseille, France

${ }^{3}$ Laboratoire des IMRCP, Université de Toulouse, CNRS UMR 5623, Université Paul Sabatier, 118 route de Narbonne 31062 Toulouse Cedex 9, France

${ }^{4}$ Center for Maritime Biosciences Studies - Institute for Sciences and Community Service, Fisheries and Marine Science Faculty, Jenderal Soedirman University, Kampus Karangwangkal, Jl. dr. Suparno, Purwokerto 53123, Indonesia

${ }^{5}$ Marine Science and Fisheries Faculty - Raja Ali Haji Maritime University, Jl. Politeknik SenggarangTanjungpinang, Riau Islands Province, 29100, Indonesia

*corresponding author

E-mail: pascal.wong-wah-chung@univ-amu.fr

\begin{abstract}
We investigated the contamination of marine plastic debris from the Indonesian Cilacap coast and the North Atlantic gyre by polycyclic aromatic hydrocarbons (PAHs) and polychlorinated biphenyls (PCBs). The mean concentrations of 15 PAHs in gyre were 58 and $142 \mathrm{ng} / \mathrm{g}$ in polyethylene (PE) and polyethylene terephthalate (PET) debris, respectively, while PE and polypropylene (PP) Indonesian debris exhibited an average content of $552 \mathrm{ng} / \mathrm{g}$ (mainly naphthalene). The mean concentration of $61 \mathrm{PCBs}$ in open ocean debris was $12.2 \mathrm{ng} / \mathrm{g}$, while coastal debris showed a worryingly high mean value of $1.4 \times 10^{4} \mathrm{ng} / \mathrm{g}$, with the notable presence of CB6, 101 and 173. PE gyre debris contained mostly high molecular weight PAHs such as benzo(g,h,i)perylene and indeno(1,2,3-cd)pyrene and low-chlorinated PCBs such as CB52, 77 and 105, whereas PET debris contained low molecular weight PAHs (mainly acenaphthylene and phenanthrene) and high-chlorinated PCBs such as CB204.
\end{abstract}

\title{
Highlights
}

- First results on the pollution of plastic debris from Indonesian coast and North Atlantic gyre

- The cumulative PAHs and PCBs' concentration is $91 \mathrm{ng} / \mathrm{g}$ in North Atlantic gyre debris.

- Indonesian coastal debris are 150 times more polluted than North Atlantic gyre ones

- PAHs' concentrations in PET from the North Atlantic gyre are slightly higher than in PE

- Fingerprints of PAHs and PCBs in marine plastic contrasted according to the microplastic source.

Keywords: Marine plastic debris, PAHs, PCBs, Indonesian Cilacap coast, North Atlantic gyre

\section{Introduction}

The accumulation of plastic debris in natural aquatic compartments is recognized as a major environmental problem because of their high amounts, their persistence and the limited knowledge available regarding their impact on ecosystems. This form of pollution has been 
evidenced in oceans as well as in seas, rivers and lakes ( Andrady, 2011; Ivar do Sul et al., 2014; Li et al., 2016; Moore, 2008; Syakti et al., 2017; Ter Halle et al., 2017; Van Sebile et al., 2015;).

It is widely accepted that plastic debris at the surface of seas and oceans, especially macroplastics, are often responsible for the death of large marine predators by accidental capture or the obstruction of the digestive system (Lavers et al. 2014; Li et al., 2016). More recent studies suggest that this adverse physical effect may also affect smaller marine organisms such as mussels and copepods (Cole et al., 2013; Van Cauwenberghe et al., 2014) or fish and bivalves sold for human consumption (Rochman et al., 2013a; Rochman et al., 2015). These results underline the potential impact of microplastics on tiny animal organisms that could be damaging to marine ecosystems.

Moreover, investigation of the potential impact of plastic debris on marine fauna is progressing through the detection in polymer debris of chemical compounds (persistent organic pollutants (POPs), additives) that are often toxic or having a chronic effect (Hirai et al., 2011; Ogata et al., 2009; Rios et al., 2007; Teuten et al., 2009). The presence of various chemicals raises the question of their potential impact on the ecosystem through diffusion in water and transfer in the aquatic species after ingestion. This aspect is of great concern, and recent studies have revealed the presence of hydrophobic organic pollutants traces in marine organisms in regions severely polluted by plastic debris (Gassel et al., 2013; Ryan, 1988; Tanaka et al., 2013; Yamashita et al., 2013). Nevertheless, scientific knowledge regarding the potential environmental impact is still sparse.

However, even if many studies have focused on the chemical content of plastic marine debris collected in different aquatic compartment areas, the nature and concentrations of detected compounds show very high variability. For instance, many studies have evidenced a proven presence of PCBs and PAHs in plastics debris (PE and PP) sampled from different locations, with concentrations in a range as broad as 1 to $10,000 \mathrm{ng} / \mathrm{g}$ of plastic debris (Hirai et al., 2011; Ivar do Sul et al., 2014; Teuten et al., 2009). But hitherto, no consistent hypothesis has been proposed to explain the considerable heterogeneity of the results.

The aim of the present paper is to broaden our knowledge on the distribution pattern and concentration variability of POPs (more specifically PAHs and PCBs) by measuring their concentrations in floating plastic debris, the latter being collected from inshore waters (Cilacap coast, Indonesia) and remote offshore waters (North-Atlantic gyre), respectively, and thus to contribute to fill the gap.

\section{Materials and methods}

\subsection{Study area and plastic debris sampling}

Macroplastics (at least one size greater than $20 \mathrm{~mm}$ ) were collected by boat in the North Atlantic subtropical gyre (NAG) in June 2015 during the French Expedition 7ème Continent. The plastic debris was collected by the sailing vessel Guyavoile in the accumulation area determined by studying a surface net tow data set (Law et al., 2010). The macroplastics were collected using a telescopic pole. Fifteen macroplastics were collected in June 2015 and the physico-chemical characteristics of some of them were given in a previous publication (Ter Halle et al., 2017). A Manta net of $75 \mathrm{~cm} \times 20 \mathrm{~cm}$ with a mesh of $300 \mu \mathrm{m}$ was used to sample plastic debris, from micro to macro size, along the Indonesian Cilacap Coast (ICC) (Syakti et al., 2017). The Cilacap region is located on the south coast of Java (Indonesia, Indian Ocean) and is surrounded by an area of slough, tributaries, mangrove swamps and intertidal land converted into rice fields. The Manta net was towed by a small boat, moving along $1.8 \mathrm{~km}$ of an imaginary transect line on the Cilacap coast, at a speed of 1.9 knots. Five distant marine areas (MT-1 to MT-5) were marked out for sampling. The collected plastic debris were sorted out from the filtered water with tweezers under a binocular microscope and stored in frozen glass sealed vials $\left(-5^{\circ} \mathrm{C}\right)$ or at 
room temperature to avoid any pre-analytical contamination. Site GPS coordinates are given in Table S1 of the Supplementary Material (SM).

\subsection{Chemicals and reagents}

Water and acetonitrile $\left(\mathrm{CH}_{3} \mathrm{CN}\right)$ for liquid chromatography analysis were Optima ${ }^{\circledR}$ LC-MS grade provided by Fisher Chemical SAS. Hexane and heptane were purchased by VWR (HPLC grade), dichloromethane by Merck (GC grade) and dimethylformamide solution of EMPARTA® for Analysis American Chemical Society with analytical purity of 99.0-99.5\%. A stock PAHs standard mixture was obtained from Supelco (Sigma Aldrich). The stock mixture contained: naphthalene, acenaphthylene, acenaphthene, fluorene, phenanthrene, anthracene, fluoranthene, pyrene, benzo(a)anthracene, chrysene, benzo(b)fluoranthene, benzo(k)fluoranthene, benzo(a)pyrene), dibenzo(a,h)anthracene, benzo(g,h,i)perylene and indeno(1,2,3-cd)pyrene at $10 \mu \mathrm{g} / \mathrm{mL}$ in $\mathrm{CH}_{3} \mathrm{CN}$.

Two stock PCB standard mixtures and standard solutions of individual PCB solutions were used. PCB Mix 20 (CB28, 31, 52, 77, 101, 105, 118, 126, 128, 138, 153, 156, 169, 170 and 180), Mix 1 (CB1 , 2, 3, 4, 6, 8, 9, 16, 18, 19, 22, 25, 28, 44, 52, 56, 66, 67, 71, 74, 82, 87, 99, 110, 138, 146, 147, 153, 173, 174, 177, 179, 180, 187, 194, 195, 199, 203 and 206), individual solutions of CB10, 14, 18, 29, 30, 78, 104, 105, 145, 149, 155, 204 and 209, and Mirex (used as an internal standard for GC-MS analysis), all at $10 \mathrm{ng} / \mu \mathrm{L}$ in cyclohexane, were purchased by Dr. Ehrenstorfer and Accustandard.

\subsection{Plastic polymer identification}

The collected plastic debris were identified by Fourier Transform Infra-Red spectroscopy (FTIR), on a Thermo Electron Nexus spectrophotometer equipped with a diamond crystal Smart Orbit TM accessory. Spectra were recorded in Attenuated Total Reflection (ATR) mode and corrected by ATR correction. Spectra were acquired in the range of 4000-450 $\mathrm{cm}^{-1}$, with 64 scans and a resolution of $4 \mathrm{~cm}^{-1}$. After identification using a spectrum database and considering certainty above $90 \%$, debris were classified by type of polymer: PE, PP, PET, polyvinyl chloride (PVC) and polystyrene (PS). Carbonyl index (CI) was also determined for PE and PP plastic debris by FTIR analysis, as described and presented elsewhere (Ter Halle et al., 2017; Syakti et al., 2017).

\subsection{Extraction of PAHs and PCBs from plastic debris}

Extraction from polymers (around $0.1 \mathrm{~g}$ ) was achieved with a $10 \mathrm{~mL}$ portion of a mixture of dichloromethane: heptane 1:1 (v:v). The suspension was maintained under mechanical stirring for 24 hours. This procedure was repeated in the same manner with a fresh $10 \mathrm{~mL}$ of the solvent mixture. A third extraction was performed to check that no residual traces of PAHs and PCBs were left as previously proposed by Choi et al., 2013. Extracts were slowly evaporated to dryness under a gentle nitrogen stream and the residue was then dissolved in $250 \mu \mathrm{L}$ of hexane containing the internal standard (Mirex), before GC-MS analysis. For liquid chromatography analyses, about $0.5 \mathrm{~mL}$ was left during the evaporation step and $50 \mu \mathrm{L}$ of dimethylformamide was added and the solution was evaporated once more. Finally, $150 \mu \mathrm{L}$ of acetonitrile was added to the residue to reach a total volume of extract of $200 \mu \mathrm{L}$, and the resulting solution was filtered on $0.2 \mu \mathrm{m}$ PTFE filter (Chromacol 4-SF-02(T), Thermo Scientific), before injection. This extraction procedure was carried out for each macroplastic debris collected in NAG and microplastic debris pooled by area in the case of ICC. Further details regarding the extraction method can be found in the SM. 


\subsection{Analysis of PAHs and PCBs}

Analyses with an Ultra Performance Liquid Chromatography (UPLC Perkin Elmer, Altus 30) equipped with a fluorescence detector were undertaken for determination of PAH concentration. An Agilent Zorbax Eclipse PAH column $(1.8 \mu \mathrm{m}, 150 \times 2.1 \mathrm{~mm}$ i.d. $)$ placed at $40{ }^{\circ} \mathrm{C}$ with a flow rate of $0.35 \mathrm{~mL} / \mathrm{min}$ was used and the injected volume was $2 \mu \mathrm{L}$. The gradient used is initially $40 \% \mathrm{~A}\left(\mathrm{CH}_{3} \mathrm{CN}\right)$ and $60 \% \mathrm{~B}\left(\mathrm{H}_{2} \mathrm{O}\right)$, after 15 minutes the gradient changes to $100 \% \mathrm{~A}$, and at $23 \mathrm{~min}$ it returns to the initial conditions. A four-channel method with different excitation and emission wavelength was developed to detect and quantify all PAHs at low concentration levels (LOQ of 1 to $6.5 \mathrm{ng} / \mathrm{g}$ of polymer) except acenaphthylene (Wong-WahChung et al., 2018).

A gas chromatography mass spectrometer (GC-MS, Perkin Elmer, Clarus 600 / 600C) equipped with a programmable temperature vaporizing (PTV) injector (programmed from 50 to $250^{\circ} \mathrm{C}$ at $200^{\circ} \mathrm{C} \mathrm{m^{-1 }}$ ) enabled the identification and quantification of the above-listed $61 \mathrm{PBCs}$, except PCB 28 and 31 which were co-eluted. A DB-5MS column $(30 \mathrm{~m} \times 0.25 \mathrm{~mm} \times 0.25 \mu \mathrm{m})$ was used and $1 \mu \mathrm{L}$ was injected in spitless mode. A specific temperature program from 60 to $280^{\circ} \mathrm{C}$ was developed to separate all PCBs: $60^{\circ} \mathrm{C}$ for $1 \mathrm{~min}$, heated to $150^{\circ} \mathrm{C}$ at $40^{\circ} \mathrm{C} / \mathrm{min}$, then to $280^{\circ} \mathrm{C}$ at $6^{\circ} \mathrm{C} / \mathrm{min}$ and held $3 \mathrm{~min}$. Source temperature was fixed at $250^{\circ} \mathrm{C}$ and compounds ionization was performed by electron ionization $(70 \mathrm{eV})$. The quadrupole mass spectrometer operated in simultaneous collection of full scan and selected ion recording (Selected Ion Full Ion mode or SIFI mode). Two GC-MS methods were developed with specific SIFI detection program to analyse 39 PCBs (using Mix 1 as reference) and other 22 PCBs (using Mix 20 and individual PCBs as reference). LOQ for PCB range from 0.08 to $4.3 \mathrm{ng} / \mathrm{g}$ of polymer. QA/QC procedures for chemical analysis can be found in the SM.

\section{Results and discussion}

\subsection{Plastic debris characterization}

Indonesian samples are micro-debris sizing a few millimeters in length and with a total mass of $1.3 \mathrm{~g}$, as described previously (Syakti et al., 2017). Infrared results showed that the 146 Indonesian pieces are made up mainly of PE $(71 \% \mathrm{w} / \mathrm{w}), \mathrm{PP}(27 \% \mathrm{w} / \mathrm{w})$ and PS (two pieces, i.e. a little less than $2 \% \mathrm{w} / \mathrm{w})$.

North Atlantic gyre samples contained 15 macroplastics each of them measuring more than a few centimeters. Different types of polymer were identified: PE (sample NA-1 to NA-9), PET (sample N-10 to N-12), PS and PVC. Samples N-10 and N-12 correspond to floating closed bottles and the PVC sample is a yellow foam float. Herein are exclusively presented the results obtained on the most abundant plastic debris, i.e. PE and PET for gyre debris (individually analysed), and PE and PP for ICC debris (pooled from Manta net samples before analysis).

\subsection{Determination of PAHs}

Concentrations of individual PAH and average concentrations of 15 PAHs in marine plastic samples collected in the North Atlantic Gyre and along the Indonesian coast are presented in Tables 1 and 2, respectively. Only quantifiable values are shown in the Tables. For NAG samples, the average concentration $(\bar{C})$ of a congener was calculated as the total concentration of this congener divided by the number of plastic debris (n) of the same chemical nature, considering null any concentration below its quantifiable limit. For ICC samples, a mean, which takes into account the mass of debris collected at each site, was calculated for any single congener. Thus, the weight-average of a given congener was calculated by dividing the total mass of this congener by the total mass of the polyolefin debris collected throughout the five sites (MT-1 to MT-5). The overall mean concentration was calculated in a similar way. It is equal to the number-average concentration of 15 PAHs contained in NAG-PE or NAG-PET and the mass-average concentration of $15 \mathrm{PAHs}$ contained in pooled ICC-samples. 


\begin{tabular}{|c|c|c|c|c|c|c|c|c|c|c|c|c|c|c|}
\hline \multirow[b]{2}{*}{$\mathrm{PAH}$ (in $\mathrm{ng} / \mathrm{g}$ ) } & \multicolumn{6}{|l|}{ PE } & \multicolumn{8}{|c|}{ PET } \\
\hline & NA-1 & NA-2 & NA-3 & NA-4 & NA-5 & NA- 6 & NA-7 & NA-8 & NA-9 & $\bar{C}(\mathrm{n}=9)$ & NA-10 & NA-11 & NA-12 & $\bar{C}(\mathrm{n}=3)$ \\
\hline Naphthalene & - & - & 2.19 & - & - & 4.73 & - & - & - & 0.77 & 15.4 & 5.98 & 1.70 & 7.71 \\
\hline Acenaphthylene & 0.33 & 0.21 & 0.32 & - & - & 0.44 & - & 0.25 & 0.2 & 0.19 & 4.30 & 103 & 138 & 82.0 \\
\hline Fluorene & 0.89 & 0.63 & 1.57 & 1.09 & - & 2.84 & - & 1.41 & - & 0.94 & 9.78 & 0.67 & 0.61 & 3.69 \\
\hline Phenathrene & 4.87 & 5.02 & 4.12 & 4.61 & 5.9 & 7.15 & 1.86 & 5.53 & 6.8 & 5.10 & 75.5 & 1.48 & 0.92 & 26.0 \\
\hline Anthracene & 1.37 & - & - & - & - & - & - & - & - & 0.15 & - & - & - & - \\
\hline Fluoranthene & 1.17 & 0.76 & 0.54 & 5.17 & 2.62 & 0.93 & - & 0.78 & - & 1.33 & 32.6 & - & - & 10.9 \\
\hline Pyrene & 1.82 & 1.74 & 1.07 & 15.0 & 7.16 & 1.07 & 3.16 & 1.4 & 2.4 & 3.87 & 21.4 & - & - & 7.15 \\
\hline Benzo(a)anthracene & 0.75 & - & - & 33.1 & 1.38 & - & - & - & - & 3.91 & 4.59 & - & - & 1.53 \\
\hline Chrysene & - & - & - & 20.8 & - & 1,52 & - & - & - & 2.48 & 6.64 & - & - & 2.21 \\
\hline Benzo(b)fluoranthene & 0.63 & 0.49 & 0.49 & 14.0 & 3.15 & 10.7 & 2.17 & 0.52 & - & 3.57 & 1.96 & - & - & 0.65 \\
\hline Benzo(k)fluoranthene & 0.47 & 0.43 & 0.42 & 2.74 & 2.61 & 2.43 & 1.82 & 0.43 & - & 1.26 & - & - & - & - \\
\hline Benzo(a)pyrene & 2.98 & 2.74 & 2.71 & 7.05 & 16.8 & 6.17 & 11.9 & 2.76 & - & 5.90 & - & - & - & - \\
\hline Dibenzo(a,h)anthracene & - & - & - & 2.11 & - & 4.34 & - & - & - & 0.72 & - & - & - & - \\
\hline Benzo(g,h,i)perylene & 1.4 & 1,27 & 1.26 & 10,6 & 7.82 & 115 & 5.45 & 1.28 & - & 16.0 & - & - & - & - \\
\hline Indeno(1,2,3-cd)pyrene & 0.86 & 0.48 & 2.19 & - & - & 98.0 & - & 0.94 & 1.8 & 11.6 & - & - & - & - \\
\hline$\sum \mathrm{PAHs}$ & 17.5 & 13.8 & 16.9 & 116 & 47.4 & 255 & 26.3 & 15.3 & 11.2 & & 172 & 111 & 142 & \\
\hline $\bar{C}(n=9$ or 3$)$ & & 58.0 & & & & & & & & & 142 & & & \\
\hline Global Mean Concentratio & 78.7 & & & & & & & & & & & & & \\
\hline
\end{tabular}

3.2.1. PAHs in North Atlantic gyre (NAG) plastic debris to NA-9). From four to thirteen PAHs were identified in each piece of PE. The presence of phenanthrene and pyrene was always confirmed at concentrations of about 1 to $15 \mathrm{ng} / \mathrm{g}$. Indeno(1,2,3-cd)pyrene and benzo(g,h,i)perylene were both detected in samples NA-1 to NA3, NA-6 and NA-8 at concentrations of around 0.5 to $98 \mathrm{ng} / \mathrm{g}$ and 1.4 to $115 \mathrm{ng} / \mathrm{g}$, respectively. A remarkably high level of the two previous PAHs can be noted in sample NA-6. Concentrations of each PAH differ by up to three orders of magnitude, from 0.2 to $115 \mathrm{ng} / \mathrm{g}$, while total PAHs ( $\Sigma 15 \mathrm{PAHs}$ ) ranged from 11.2 to $255 \mathrm{ng} / \mathrm{g}$, with an average concentration of $\overline{\mathrm{C}}=58 \mathrm{ng} / \mathrm{g}$. Such levels of concentration in total PAHs agree with previous studies carried out on PE and PP plastic debris collected in the North Pacific central gyre (Hirai et al., 2011). PAHs were also detected in PET debris (NA-10 to NA-12), with the systematic presence of naphthalene, acenaphthylene, fluorene and phenanthrene. Five more PAHs were identified but only in NA-10, namely fluoranthene, pyrene, benzo(a)anthracene, chrysene and benzo(b)fluoranthene. NA-10 is clearly different from the other two samples in terms of PAHs levels and pattern. The concentrations of individual PAH were also distributed over a wide range, i.e. 0.6 to $138 \mathrm{ng} / \mathrm{g}$. Total PAHs extracted from PET debris amounted from $111 \mathrm{ng} / \mathrm{g}$ for NA-11 to $172 \mathrm{ng} / \mathrm{g}$ for NA-10, which is similar to the highest concentrations measured in PE NAG samples. The PAHs concentrations in the three PET samples averaged $142 \mathrm{ng} / \mathrm{g}$.

The comparison of the amounts of each PAH in one or the other gyre polymers shows that individual PAHs are unequally distributed between PE and PET. The mean concentrations are notably greater in PET than in PE for naphthalene ( $7.7 \mathrm{vs} 0.8 \mathrm{ng} / \mathrm{g}$ ), acenaphthene ( $82 \mathrm{vs} 0.2$ $\mathrm{ng} / \mathrm{g}$ ), fluorene (3.7 vs $0.9 \mathrm{ng} / \mathrm{g}$ ), phenanthrene (26 vs $5.1 \mathrm{ng} / \mathrm{g}$ ), fluoranthene (10.9 vs $1.3 \mathrm{ng} / \mathrm{g}$ ) and pyrene (7.2 vs $3.9 \mathrm{ng} / \mathrm{g})$.

When comparing the overall concentrations of PAHs in the two types of polymer, it is found that the average amount of PAHs adsorbed onto PET debris is 2.5 times larger than PE (142 vs $58 \mathrm{ng} / \mathrm{g}$, respectively).

\subsubsection{PAHs in Indonesian Cilacap coastal (ICC) plastic debris}

From Table 2, it can be seen that PAHs were detected in all five Manta net samples collected from the coast. On the one hand, ten to thirteen PAHs were identified in each sample, nine of which were systematically evidenced (naphthalene, fluorene, pyrene, fluoranthene, pyrene, benzo(k)fluoranthene, benzo(a)pyrene, dibenzo(a,h)anthracene and benzo(g,h,i)perylene). On 
the other hand, anthracene and benzo(a)anthracene were not detected in any of the Indonesian samples. The concentrations of each PAH showed a very wide disparity, rising from $0.6 \mathrm{ng} / \mathrm{g}$ for the lowest one (chrysene in MT2), to $1.3 \times 10^{3} \mathrm{ng} / \mathrm{g}$ for the highest (naphthalene in MT-4). The mean concentrations of $\Sigma 15$ PAHs were $153 \mathrm{ng} / \mathrm{g}$ in MT-5 (the least contaminated sample) and $2.0 \times 10^{3} \mathrm{ng} / \mathrm{g}$ in MT-4 (the most contaminated one). This is in accordance with concentrations determined in plastic debris collected in the Japanese coast area and urban beaches (Hirai et al., 2011; Rios et al., 2014; Teuten et al., 2009). This behaviour can be attributed to the proximity of anthropogenic activities. This is especially patent for MT-4, which is close to boat transport and fishing. It is noteworthy that naphthalene was the most abundant $\mathrm{PAH}$, its mean concentration (around $315 \mathrm{ng} / \mathrm{g}$ ) counting for more than half of the overall mean PAH concentration (around $552 \mathrm{ng} / \mathrm{g}$ ).

Table 2

Concentrations of PAHs in ng per gram in Indonesian Cilacap coast plastic debris.

\begin{tabular}{lllllll}
\hline PAH (in ng/g) & MT-1 & MT-2 & MT-3 & MT-4 & MT-5 & $\bar{C}(\mathrm{n}=5)$ \\
\hline Naphthalene & 421 & 162 & 83.4 & $1.26 \times 10^{3}$ & 72.6 & $\mathbf{3 1 5}$ \\
Acenaphthylene & - & 3.86 & - & - & - & $\mathbf{0 . 2 6}$ \\
Fluorene & 43.6 & 3.75 & 2.23 & 23.2 & 4.07 & $\mathbf{1 1 . 2}$ \\
Phenathrene & 45.4 & 32.3 & 10.6 & 147 & 27.4 & $\mathbf{4 7 . 6}$ \\
Anthracene & - & - & - & - & - & - \\
Fluoranthene & 45.1 & 12.7 & 16.7 & 163 & 11.9 & $\mathbf{4 1 . 2}$ \\
Pyrene & 62.6 & 11.2 & 17.6 & 148 & 10.9 & $\mathbf{4 0 . 0}$ \\
Benzo(a)anthracene & - & - & - & - & - & - \\
Chrysene & 22.6 & 0.60 & 8.69 & - & - & $\mathbf{3 . 4 1}$ \\
Benzo(b)fluoranthene & - & 5.05 & - & - & 4.90 & $\mathbf{3 . 0 2}$ \\
Benzo(k)fluoranthene & 20.7 & 4.64 & 3.31 & 17.9 & 2.48 & $\mathbf{7 . 2 1}$ \\
Benzo(a)pyrene & 52.8 & 12.5 & 9.25 & 50.2 & 3.86 & $\mathbf{1 7 . 9}$ \\
Dibenzo(a,h)anthracene & 44.8 & 8.89 & 4.81 & 69.2 & 11.5 & $\mathbf{2 3 . 7}$ \\
Benzo(g,h,i)perylene & 72.1 & 19.9 & 9.26 & 58.8 & 3.90 & $\mathbf{2 1 . 9}$ \\
Indeno(1,2,3-cd)pyrene & 57.7 & 30.2 & 8.22 & 62.1 & - & $\mathbf{1 9 . 4}$ \\
$\sum$ PAHs & $\mathbf{8 8 8}$ & $\mathbf{3 0 8}$ & $\mathbf{1 7 4}$ & $\mathbf{2} \times \mathbf{1 0}$ & $\mathbf{1 5 3}$ & $\mathbf{5 5 2}$ \\
Global Mean Concentration: & $\mathbf{5 5 2}$ & & & & &
\end{tabular}

Note: Average concentrations $(\bar{C})$ are weighted arithmetic means, taking into account the mass of debris collected at each site.

\subsection{3.- Fingerprint of PAHs}

Attention was paid to the distribution between heavy molecular weight (more than three fused aromatic rings) and low molecular weight (2-3 fused aromatic rings) PAHs (H- and L-PAHs, respectively), as presented in Figs. 1 and 2. Percentages of H-PAHs (or L-PAHs) were calculated as the ratio between H-PAH (or L-PAH) concentration in ng/g divided by total PAH concentration in $\mathrm{ng} / \mathrm{g}$, multiplied by 100 . 


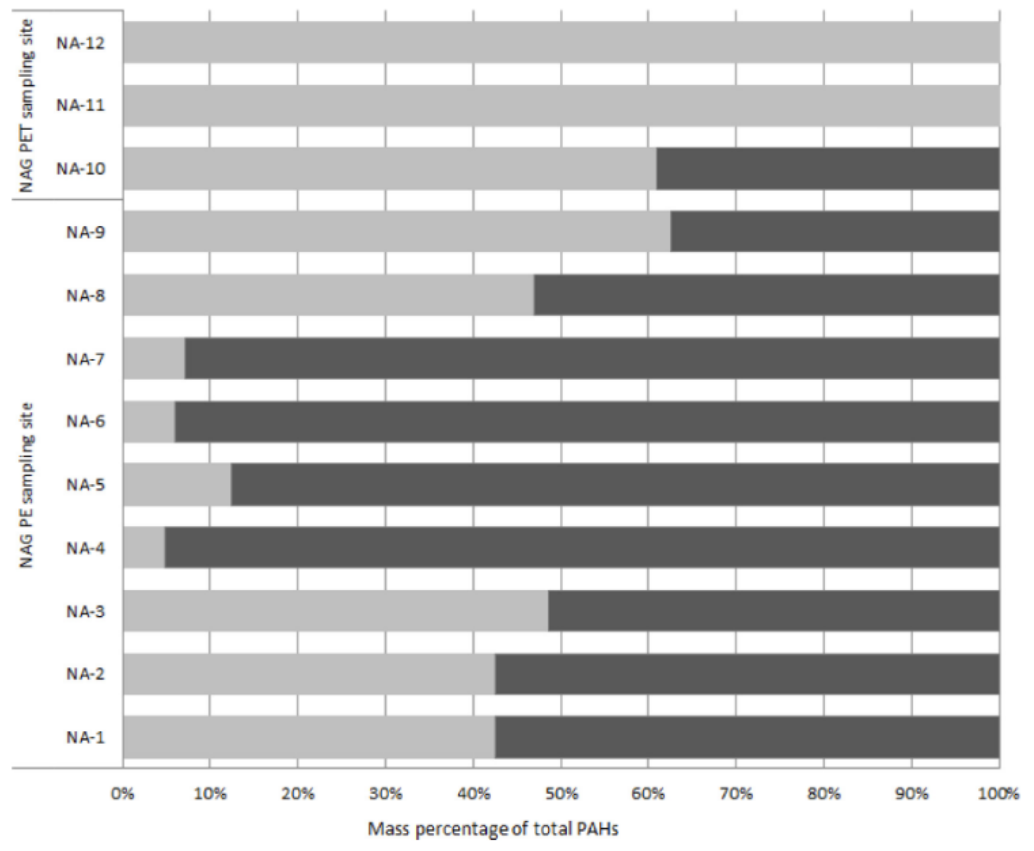

This enabled us to evidence some singularities between all plastic debris. On one hand, it appeared that NAG PE samples mainly contain H-PAHs with concentration percentages in the range of 37 (NA-9) to 95\% (NA-4), linked to the presence of markedly higher amounts of benzo(g,h,i)perylene and indeno(1,2,3-cd)pyrene (see Table 1). On the other hand, PET NAG debris were mainly polluted by L-PAHs (from 61 (NA-10) to 100\% (NA-11 and NA-12)) as well as ICC plastic debris (from 55 (MT-3) to $72 \%$ (MT-4)).

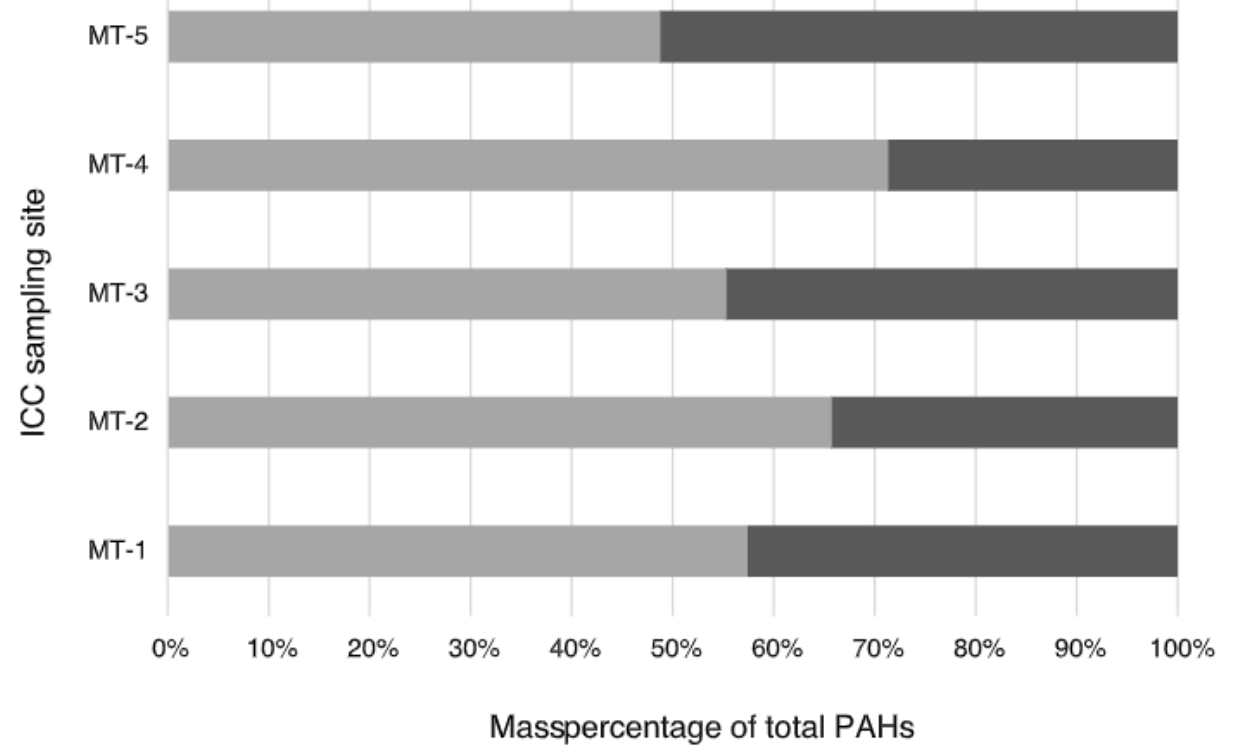

Fig. 2. Distribution of PAHs in percentage in Indonesian Cilacap coast plastic debris. L-PAHs (grey), H-PAHs (black).

Acenaphthylene and phenanthrene account for the highest concentrations in NAG PET debris 


\subsection{Determination of $P C B s$}

In this part, the research focused on 61 PCBs congeners, among which 17 were detected in NAG samples and 31 in ICC samples (Tables 3 and 4). Only PCBs that were present in a quantifiable amount are reported in these tables.

\subsubsection{PCBs in North Atlantic gyre debris}

According to Table 3, PCBs were quantified in six of the nine PE samples (i.e. NA-1 to NA-3, NA-6, NA-8 and NA-9), while the presence of PCBs was confirmed in all three PET samples.

Table 3

Concentrations of PCBs in ng per gram in North Atlantic gyre plastic debris.

\begin{tabular}{|c|c|c|c|c|c|c|c|c|c|c|c|}
\hline \multirow[b]{2}{*}{ PCB (in $n g / g$ ) } & \multicolumn{8}{|l|}{$\mathrm{PE}$} & \multicolumn{3}{|l|}{ PET } \\
\hline & NA-1 & NA-2 & NA-3 & NA-6 & NA-8 & NA-9 & $\bar{C}(n=9)$ & NA-10 & NA-11 & NA-12 & $\bar{C}(\mathrm{n}=3)$ \\
\hline CB1 & - & - & - & - & - & 14.9 & 1.66 & - & - & - & - \\
\hline CB2 & 0.59 & - & - & - & - & - & 0.07 & - & - & - & - \\
\hline CB10 & - & - & 3.47 & - & - & - & 0.38 & 0.72 & 1.31 & - & 0.68 \\
\hline CB18 & - & - & - & - & - & - & - & - & 0.13 & - & 0.04 \\
\hline CB19 & - & - & - & - & - & 4.3 & 0.48 & - & - & - & - \\
\hline CB22 & - & - & - & - & - & 8.5 & 0.94 & - & 1.38 & - & 0.46 \\
\hline CB28+31 & - & - & - & - & - & - & - & 0.54 & 0.94 & 1.08 & 0.85 \\
\hline CB30 & - & 1.73 & - & - & 0.77 & - & 0.27 & - & - & - & - \\
\hline CB52 & - & - & 11.0 & 50.4 & - & - & 6.82 & - & - & - & - \\
\hline CB77 & - & - & - & - & - & 10.2 & 1.13 & - & - & - & - \\
\hline CB78 & - & - & - & - & 2.52 & - & 0.28 & - & - & - & - \\
\hline CB87 & - & - & - & - & - & 12.9 & 1.43 & 1.44 & 2.42 & - & 1.29 \\
\hline CB105 & - & - & 1.24 & 1.43 & - & 7.9 & 1.17 & - & - & - & - \\
\hline CB156 & - & - & - & - & - & - & - & - & 2.59 & - & 0.86 \\
\hline CB174 & - & 4.68 & - & - & - & - & 0.52 & - & - & - & - \\
\hline CB204 & - & - & - & - & - & - & - & - & 15.1 & - & 5.02 \\
\hline$\sum$ PCBs & 0.59 & 6.41 & 15.7 & 51.8 & 3.29 & 58.7 & & 2.7 & 23.8 & 1.08 & \\
\hline $\bar{C}(\mathrm{n}=9$ or 3$)$ & & & 15.2 & & & & 9.21 & & & & \\
\hline Global Mean Conc & entratio & $\mathrm{n}: 12.2$ & & & & & & & & & \\
\hline
\end{tabular}

1 to a maximum of 6 congeners were quantified in PE samples, and 2 to 3 congeners on average per sample. CB 105 was the most frequently detected (it was found in three samples). The concentrations of each PCB ranged from 0.6 to $50 \mathrm{ng} / \mathrm{g}$, while concentrations of $\Sigma$ PCBs ranged from 0.6 (NA-1, the least polluted sample) to $59 \mathrm{ng} / \mathrm{g}$ (NA-9, the most polluted sample). Similar concentrations were determined in plastic debris collected in the North Central Pacific gyre (Hirai et al., 2011; Rios et al., 2010), revealing some uniformity of PCB content in the plastics drifting in open oceans.

PCBs were also detected in PET debris (NA-10 to NA-12), with the systematic presence of CB 28+31. Other PCBs were mainly identified in NA11, namely CB 10, 18, 22, 87, 156 and 204, which clearly distinguished this sample from the two others. In PET debris, PCB concentrations were within a very narrow range of concentrations from 0.5 to $2.6 \mathrm{ng} / \mathrm{g}$, except for two values, i.e. 0.1 to $15.1 \mathrm{ng} / \mathrm{g}$. Concentrations of $\Sigma \mathrm{PCBs}$ were of the same order of magnitude (from 1.1 to $24 \mathrm{ng} / \mathrm{g}$ ) as in PE debris.

\subsubsection{PCBs in Indonesian coastal plastic debris}

PCBs were detected in all ICC samples, as shown in Table 4. CB173 was the most abundant $\mathrm{PCB}$, its average concentration, i.e. $8.84 \times 10^{3} \mathrm{ng} / \mathrm{g}$, counting for more than $63 \%$ of the average 
concentration of total-PCBs. Other PCBs often detected in these samples were CB 6, 10, 29, 77,147 and particularly CB101, with a significantly high mean concentration $\left(3.08 \times 10^{3} \mathrm{ng} / \mathrm{g}\right.$, representing about $22 \%$ of total-PCBs mean concentration). Individual CBs concentrations were in the range $0.9 \times 10^{3}$ to $1.6 \times 10^{4} \mathrm{ng} / \mathrm{g}$, while total-PCBs concentrations extended from $1.3 \times 10^{3}$ for MT-3 to $1.9 \times 10^{4} \mathrm{ng} / \mathrm{g}$ for MT- 1 . The mean concentration of $\Sigma \mathrm{PCBs}$ was $1.4 \times 10^{4}$ $\mathrm{ng} / \mathrm{g}$. These worrying concentrations are many times higher than those cited in the literature for the coastal area and urban beaches (Frias et al., 2010; Hirai et al., 2011; Rios et al., 2014; Teuten et al., 2009; Zhang et al., 2015).

Table 4

Concentrations of PCBs in ng per gram in Indonesian Cilacap coast plastic debris.

\begin{tabular}{|c|c|c|c|c|c|c|}
\hline PCB (in $n g / g$ ) & MT-1 & MT-2 & MT-3 & MT-4 & MT-5 & $\bar{C}(n=5)$ \\
\hline CB1 & - & - & 42.0 & 208 & 2.18 & 40.6 \\
\hline CB3 & 7.45 & - & - & - & - & 0.79 \\
\hline CB4 & - & - & - & $1.87 \times 10^{3}$ & 364 & 511 \\
\hline CB6 & 10.6 & - & 55.2 & 261 & 214 & $1.68 \times 10^{3}$ \\
\hline CB10 & - & - & - & $1.02 \times 10^{3}$ & - & 171 \\
\hline CB16 & - & 2.29 & 44.3 & - & 6.37 & 8.69 \\
\hline CB18 & - & 48.6 & 0.94 & 72.3 & 74.9 & 56.4 \\
\hline CB22 & - & - & 36.9 & 404 & - & 71.6 \\
\hline CB25 & - & - & 58.5 & - & - & 6.67 \\
\hline CB28+31 & - & 8.97 & - & - & 82.8 & 45.9 \\
\hline CB29 & $1.61 \times 10^{3}$ & - & 28.6 & - & 45.1 & 198 \\
\hline CB44 & - & 1.83 & - & - & - & 0.12 \\
\hline CB52 & - & $3.02 \times 10^{3}$ & - & - & - & 201 \\
\hline CB56 & - & 12.6 & - & - & 16.6 & 9.92 \\
\hline CB66 & - & 16.0 & - & 37.4 & - & 7.30 \\
\hline CB67 & 21.7 & - & - & 113 & - & 21.2 \\
\hline CB74 & - & 2.79 & - & 167 & - & 28.1 \\
\hline CB77 & 928 & - & 126 & 492 & 100 & 249 \\
\hline CB82 & 256 & - & - & - & - & 27.0 \\
\hline CB101 & $1.55 \times 10^{4}$ & 131 & 508 & $2.59 \times 10^{3}$ & $1.72 \times 10^{3}$ & $3.08 \times 10^{3}$ \\
\hline CB104 & 256 & - & - & - & - & 27.1 \\
\hline CB138 & - & 14.4 & - & - & - & 0.96 \\
\hline CB146 & 2.13 & - & - & - & - & 0.22 \\
\hline CB147 & - & 3.66 & 305 & 929 & 106 & 248 \\
\hline CB149 & - & - & 19.3 & - & - & 2.20 \\
\hline CB153 & 14.6 & - & 32.9 & - & 28.5 & 20.9 \\
\hline CB173 & 42.2 & 56.9 & - & $1.57 \times 10^{3}$ & $1.56 \times 10^{4}$ & $8.84 \times 10^{3}$ \\
\hline CB177 & 19.7 & - & - & - & - & 2.08 \\
\hline CB179 & - & 17.5 & 18.2 & - & - & 3.24 \\
\hline CB180 & - & 38.6 & - & - & - & 2.57 \\
\hline$\sum \mathrm{PCB}$ & $1.8 \times 10^{4}$ & $3.37 \times 10^{3}$ & $1.27 \times 10^{3}$ & $9.74 \times 10^{3}$ & $1.84 \times 10^{4}$ & $1.40 \times 10^{4}$ \\
\hline
\end{tabular}

Note: Average concentrations $(\bar{C})$ are weighted arithmetic means, taking into account the mass of debris collected 


\subsubsection{Fingerprint of $\mathrm{PCB}$}

The PCB distribution between high-chlorinated ( $\geq 5$ chlorine atoms i.e. from CB82 to CB209) and low-chlorinated ( $\leq 4$ chlorine atoms i.e. from CB1 to CB81) congeners (HC- and LC-PCBs, respectively) was then examined (Rodriguez et al., 2016). The distributions of PCB homologs are presented in Figs. 3 and 4. Fig. 3 evidences that PE NAG samples overwhelmingly contain LC-PCBs (from 64 (NA-9) to 100\% (NA-1, NA-2 and NA-8)), more specifically tri- and tetrachlorinated congeners for all samples, except for sample NA-1 which contains monochlorinated PCBs exclusively. For PET samples, it is hard to clearly identify a particular trend for the distribution of PCB homologs, even if HC-PCBs were predominantly detected with concentration percentages ranging from 53 (NA10) to 84\% (NA-11).

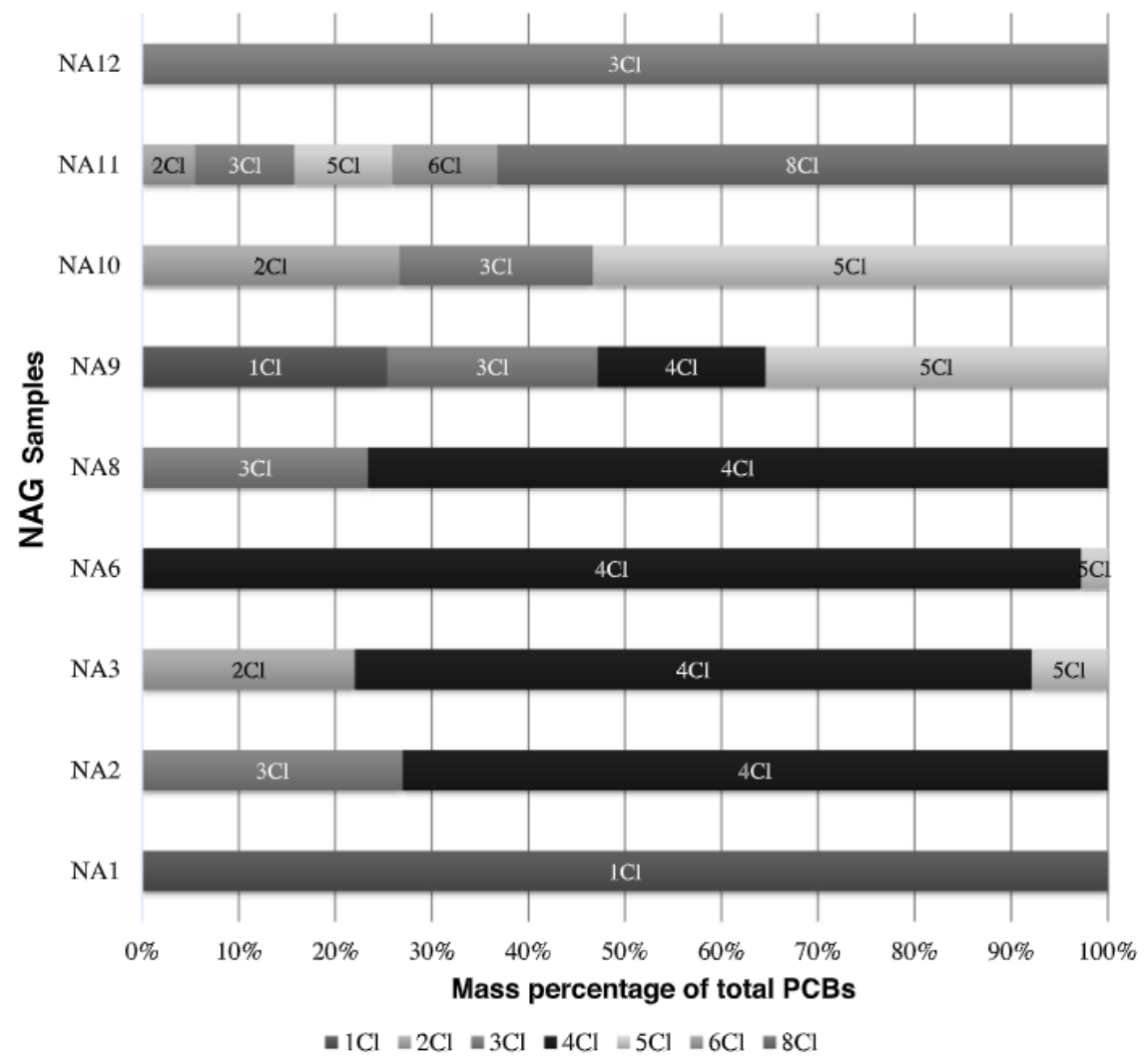

However, Fig. 4 clearly shows that tetra-, penta-, hexa- and hepta-chlorinated congeners are the most abundant PCBs in all ICC samples. This trend can be correlated to the homologs pattern of Arochlor 1254 and 1260, Monsanto technical mixtures extensively marketed and used (Frame et al., 1996) with the predominant presence of HC-PCBs (52\% (MT-4) to 95\% (MT$5)$ ).

\section{Discussion}

All marine plastic debris studied contained PAHs and PCBs. According to the sampling location of debris and to its polymeric nature, PAH and PCB content varied widely regarding: $(i)$ the pattern, (ii) the individual concentrations, and (iii) the sum concentrations.

The difference between the relatively high PAH and PCB concentrations observed in coastal debris and the much lower concentrations observed in gyre debris may be explained by three parameters, the residential time in the marine environment, which is closely associated with the diffusion rate and the 
al., 2013; Frias et al., 2010; Hirai et al., 2010; Hüffer et al., 2018; Rios et al., 2007; Rios et al., 2010; Rochman et al., 2013b; Rusina et al., 2010; Zhang et al., 2015).

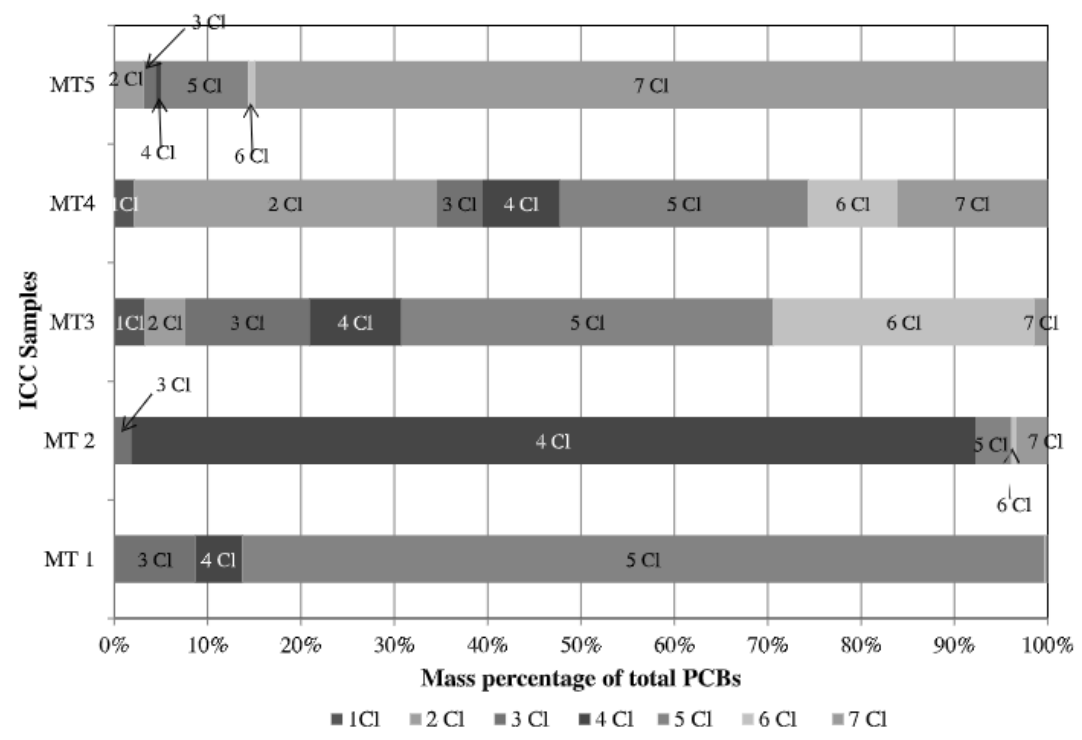

Fig. 4. Distribution of $\mathrm{PCB}$ homologs in percentage in Indonesian Cilacap coast plastic debris.

(i) As the plastic debris drift away towards remote oceans, plastics may undergo two processes yielding a decrease of contaminants adsorbed. On the one hand, this is actually expected to happen because plastic debris are much less exposed to contaminants, since the water of more remote locations gets gradually cleaner and much less affected by natural or anthropogenic pollution. Such desorption process is controlled by the diffusion. On the other hand, PAHs and PCBs are tied to plastics by physical hydrophobic interactions, which decrease due to the wellknown photo oxidation of the polymeric matrix such as polyolefins (Gardette, 1995; Gardette et al., 2013). It is worth recalling that solar light exposure could be responsible for major structural changes in polyolefin polymers: formation of polar groups on chains, chain scission, crosslinking, cracking, erosion and fragmentation (Gardette, 1995; Gardette et al., 2013). Such changes could significantly alter the sorption properties of the polymer leading to the decrease in concentrations of PAHs and PCBs in the debris, as recently reported for PS microplastic particles (Hüffer et al., 2018). This hypothesis is supported by CI values of plastic debris that are often considered as representative of the photo oxidative state of the polymer: the higher the values are, the higher the polymer is photooxidized. CI values that were determined for NAG PE samples (around 0.7) are indeed ten times higher than those determined for ICC PE and PP samples (around 0.08), according to previous works (Syakti et al., 2017; Ter Halle et al., 2017). This assumption needs further experiments to confirm the sorption alterations of plastic debris for POPs under solar light exposure. Secondly, it is possible that some chemical, photochemical or microbial degradation of POPs takes place, decreasing their content in these plastics, as described in point 3.

(ii) The microscopic size of coastal debris provides a surface area and an external shell volume that are, per unit of mass, much larger than that of gyre's macroscopic debris, greatly enhancing their adsorption capacity. Indeed, in a forthcoming work, we show that an external shell, which is less than 200 micrometers thick, constitutes the only volume that is effective for the uptake of POPs.

(iii) The erosion process through sea transport also plays a significant role in the much lower pollution of NAG debris as compared to ICC debris because of the loss of the surface layer heavily contaminated with pollutants favoured by photochemical and mechanical processes. 
2- Another interesting difference, which was observed between polyolefin samples collected from the coast and polyolefin samples collected from the open ocean, is the contrasting distribution of the PCB content (LC and HC-PCBs) as well as PAH fractions (L- and H-PAHs). HC-PCBs and L-PAHs predominate in the coastal samples, while LC-PCBs and H-PAHs are prominent in the gyre samples. Even if plastic debris were collected from different ocean basins, that could justify such disparity, PAH distribution suggests a petrogenic signature in coastal debris and a pyrogenic one in gyre debris, as previously mentioned respectively for Japanese costal debris and Central Pacific Gyre samples (Hirai et al., 2011; Rios et al., 2012). In addition, the predominance of HC-PCBs in coastal samples and of LC-PCBs in open ocean samples is consistent with results reported by the same authors (Hirai et al., 2011; Rios et al., 2012).

The difference in distribution for PCBs may be explained by some sorption and photodegradation processes. In fact, it has been reported that highly chlorinated congeners have great affinity for PE-like polymers. The equilibrium sorption values (Choi et al., 2013) and the diffusion coefficients of PCBs (Rusina et al., 2010) should favored HC-PCBs in open ocean samples and LC-PCBs in coastal ones. Nevertheless, assuming that PCBs may undergo sunlight-induced chemical degradation, some HC-PCBs could be converted to lower chlorinated ones (Miao et al., 1999). Consequently, the proportion between LC-PCBs and HCPCBs is gradually inverted.

The higher percentage of H-PAHs in NAG PE samples could be justified by the higher affinity between H-PAHs and PE (high equilibrium sorption coefficient) and the more efficient diffusion of L-HAPs in PE (high diffusion coefficients): indeed, the PE-water partitioning coefficient increases with PAH molar mass, as reported by Choi et al., 2013 while their diffusion coefficient decreases (Fries et al., 2011; Rusina et al., 2010). Such a relationship, associated with a long residence time in seawater (as is suggested by relatively high CI values), could favour the accumulation of H-PAHs to the detriment of L-PAHs. This hypothesis is consistent with the field experiments of Rochman and co-authors that highlighted the release of L-PAHs and the continuous accumulation of H-PAHs (Rochman et al., 2013b). In line with this interpretation is the low content of H-PAHs found in ICC plastic debris. The involvement of any photochemical process allowing the transformation of L-PAHs to H-PAHs, must be discarded since it has been shown that the photodegradation of PAHs on soil leads to oxidized compounds (Marquès et al., 2017). However, the concentration decrease of L-PAHs in open ocean debris could be ascribed to their more efficient phototransformation in comparison to HPAHs, as described previously on soils (Marquès et al., 2016). Such an assumption needs further experiments on the behaviour of POPs on plastic debris for it to be confirmed.

3- Although of the same polymeric nature and from the same location, some samples displayed drastically different contents. This cannot be justified by a probable difference in their residential time (because of similar IC values), since it must be equivalent and hence should not have such an impact. However, what happens to plastics before being sampled is completely unknown. For instance, some NAG debris can be either transported from the American coasts or from European ones, having thus initially different composition (additives, flame retardants, etc.), and having then be in contact with different aquatic environments affected differently by anthropogenic activities.

4- The significant qualitative and quantitative (i.e. congener compositions and concentrations) differences between PE and PET samples, both issued from the gyre, can be attributed to the different tendencies of these polymers to adsorb PAHs and PCBs, in addition to other processes mentioned above. Rochman and coworkers (Rochman et al., 2013b) pointed out that PS adsorbed low molecular weight PAHs more efficiently than PP. These results supported the property of aromatic polymers, PET being one of them, to adsorb at their surface more efficiently L-PAHs than do polyolefins, such as PE, through strong hydrophobic interactions generated by the presence of $\pi$ bonds in both compounds. Concerning the content of PCBs, it 
seems reasonable to assume that similar interactions could also explain the difference between $\mathrm{PE}$ and PET gyre samples.

\section{Conclusion}

The study of PAHs and PCBs contained in plastic debris collected in different areas clearly showed differences in concentration and distribution. Coastal debris was revealed to contain high concentrations of PAHs and PCBs, with a predominance of low molecular weight PAHs and high-chlorinated-PCBs, while gyre plastic debris are less polluted samples but contain mainly high molecular weight PAHs and low-chlorinated-PCBs. This suggests the degradation or release of chemicals during transport by ocean currents and/or atmospheric air, to which can add the chemical and physical phototransformation of the plastic debris. It is worth recalling that microplastics, and even more so, nanoplastics (particles smaller than $100 \mathrm{~nm}$ in size), may be transported in air. Thus, the presence of highly toxic hydrophobic compounds was confirmed in marine plastic debris from the Indonesian Cilacap coast, in huge concentrations, and the North Atlantic gyre, in quite low concentrations. Acting as a sink of PAHs and PCBs, plastic debris may pose threats to the marine ecosystem, by their potential to release these POPs into either remote seawater or the organisms of aquatic animals, after their ingestion. This pathway adds up to other routes such as ventilation of water and food ingestion. In particular, the presence of high molecular weight PAHs in plastic debris collected in remote oceans, such as the carcinogenic benzo(a)pyrene, merits serious consideration from scientists and political authorities. The high PCB concentrations in Indonesian plastic debris, especially CB52, 101 and 153, which are on the list of the European six indicators, is a matter of major concern regarding the pollution levels caused by plastics in this part of the world (Jambeck et al., 2015). The detection of CB77 and CB105 in plastic debris collected in the gyre is also of great concern, because both are listed in the European Water Framework Directive (2013/39/EU) as priority substances and are considered as dioxin-like compounds. In addition, the presence of LC-PCBs, such as CB52 and 105, in NAG debris is worrying because of their possible accumulation in marine organisms, as demonstrated by Yamashita et al., 2011.

\section{Acknowledgements}

We would like to express our gratitude to the Algerian government for Exceptional National Program grant (PNE 198/2016-2017), Total Corporate Foundation, the Indonesia Program DIPA UNSOED (DIPA/023.04.2.189899/2014), the French $7^{\text {th }}$ Continent Expedition association for debris sampling and PerkinElmer for providing their HPLC system.

\section{References}

Andrady A.L., 2011. Microplastics in the marine environment. Mar. Pollut. Bull. 62, 15961605.

Choi Y., Cho Y.-M., Luthy R.G., 2013. Polyethylene-Water Partitioning Coefficients for Parent- and Alkylated-Polycyclic Aromatic Hydrocarbons and Polychlorinated Biphenyls. Environ. Sci. Technol. 47, 6943-6950.

Cole M., Lindeque P., Fileman E., Halsband C., Goodhead R., Moger J., Galloway T.S., 2013. Microplastic ingestion by zooplankton. Environ. Sci. Technol. 47, 6646-6655.

Frias J.P.G.L., Sobral P., Ferreira A.M., 2010. Organic pollutants in microplastics from two beaches of the Portuguese coast. Mar. Pollut. Bull. 60, 1988-1992. 
Fries E., Zarfl C., 2012. Sorption of polycyclic aromatic hydrocarbons (PAHs) to low and high density polyethylene (PE). Environ. Sci. Pollut. Res. 19, 1296-1304.

Gassel M., Harwani S., Park J.-S., Jahn A., 2013. Detection of nonylphenol and persistent organic pollutants in fish from the North Pacific Central Gyre. Mar. Pollut. Bull. 73, 231-242.

Hirai H., Takada H., Ogata Y., Yamashita R., Mizukawa K., Saha M., Kwan C., Moore C., Gray H., Laursen D., Zettler E.R., Farrington J.W., Reddy C.M., Peacock E.E., Ward M.W., 2011. Organic micropollutants in marine plastics debris from the open ocean and remote and urban beaches. Mar. Pollut. Bull. 62, 1683-1692.

Hüffer T., Weniger A.-K., Hofmann T., 2018. Sorption of organic compounds by aged polystyrene microplastic particles. Environ. Pollut. 236, 218-225.

Ivar do Sul J.A., Costa M.F., 2014. The present and future of microplastic pollution in the marine environment. Environ. Pollut. 185, 352-364.

Jambeck J.R., Geyer R., Wilcox C., Siegler T.R., Perryman M., Andrady A., Narayan R., Law K.L., 2015. Marine pollution. Plastic waste inputs from land into the ocean. Science 347, 768771.

Lavers J.L., Bond A.L., Hutton I., 2014. Plastic ingestion by Flesh-footed Shearwaters (Puffinus carneipes): Implications for fledgling body condition and the accumulation of plasticderived chemicals. Environ. Pollut. 187, 124-129.

Law K.L., Morét-Ferguson S., Maximenko N.A., Proskurowski G., Peacock E.E., Hafner J., Reddy C.M., 2010. Plastic accumulation in the North Atlantic subtropical gyre. Science 329, 1185-1188.

Li W.C., Tse H.F., Fok L., 2016. Plastic waste in the marine environment: a review of sources, occurrence and effect. Sci. Total Environ. 566-567, 333-349.

Marquès M., Mari M., Sierra J., Nadal M., Domingo J.L., 2017. Solar radiation as a swift pathway for PAH photodegradation: A field study. Sci. Total Environ., 581-582, 530-540.

Marquès M., Mari M., Audi-Miro C., Sierra J., Soler A., Nadal M., Domingo J.L., 2016. Photodegradation of polycyclic aromatic hydrocarbons in soils under a climate change base scenario. Chemosphere 148, 495-503.

Miao X.S., Chu S.G., Xu X.B., 1999. Degradation pathways of PCBs upon UV irradiation in hexane. Chemosphere 39, 1639-1650.

Moore C.J., 2008. Synthetic polymers in the marine environment: A rapidly increasing, longterm threat. Environ. Res. 108, 131-139.

Ogata Y., Takada H., Mizukawa K., Hirai H., Iwasa S., Endo S., Mato Y., Saha M., Okuda K., Nakashima A., Murakami M., Zurcher N., Booyatumanondo R., Zakaria M.P., Dung le Q., Gordon M., Miguez C., Suzuki S., Moore C., Karapanagioti H.K., Weerts S., McClurg T., Burres E., Smith W., Van Velkenburg M., Lang J.S., Lang R.C., Laursen D., Danner B., 
Stewardson N., Thompson R.C., 2009. International Pellet Watch: global monitoring of persistent organic pollutants (POPs) in coastal waters. 1. Initial phase data on PCBs, DDTs, and HCHs. Mar. Pollut. Bull. 58, 1437-1446.

Rios L. M., Moore C., Jones P. R., 2007. Persistent organic pollutants carried by synthetic polymers in the ocean environment. Mar. Pollut. Bull. 54, 1230-1237.

Rios L. M., Jones P. R., Moore C., Narayan U. V., 2010. Quantification of persistent organic pollutants adsorbed on plastic debris form the Northern Pacific Gyre's "eastern garbage patch". J. Environ. Monit. 12, 2226-2236.

Rochman M.C., Hoh E., Kurobe T., Teh S.J., 2013a. Ingested plastic transfers hazardous chemicals to fish and induces hepatic stress. Sci. Rep. 3:3263, 1-10.

Rochman M.C., Hoh E., Hentschel B. T., Kaye S., 2013b. Long-Term Field Measurement of Sorption of Organic Contaminants to Five Types of Plastic Pellets: Implications for Plastic Marine Debris. Environ. Sci. Technol. 47, 1646-1654.

Rochman M.C., Tahir A., Williams S.L., Baxa D.V., Lam R., Miller J.T., Teh F.-C., Werorilangi S., Teh S.J., 2015. Anthropogenic debris in seafood: Plastic debris and fibers from textiles in fish and bivalves sold for human consumption. Sci. Rep. 5:14340, 1-10.

Rodriguez E.A., Li X., Lehmler H.-J., Robertson L.W., Duffel M.W., 2016. Sulfation of Lower Chlorinated Polychlorinated Biphenyls Increases Their Affinity for the Major Drug-Binding Sites of Human Serum Albumin. Environ. Sci. Technol. 50, 5320-5327.

Rusina T.P., Smedes F., Klanova J., 2010. Diffusion Coefficients of Polychlorinated Biphenyls and Polycyclic Aromatic Hydrocarbons in Polydimethylsiloxane and Low-Density Polyethylene Polymers. J. Appl. Polym. Sci. 116, 1803-1810.

Ryan P.G., 1988. Intraspecific Variation in Plastic Ingestion by Seabirds and the Flux of Plastic Through Seabird Populations. The Condor 90, 446-452.

Syakti A. D., Bouhroum R., Hidayati N.V., Koenawan C.J., Boulkamh A., Sulistyo I., Lebarillier S., Akhlus S., Doumenq P., Wong-Wah-Chung P., 2017. Beach macro-litter monitoring and floating microplastic in a coastal area of Indonesia. Mar. Pollut. Bull. 122, 217225.

Tanaka K., Takada H., Yamashita R., Mizukawa K., Fukuwaka M.-A., Watanuki Y., 2013. Accumulation of plastic-derived chemicals in tissues of seabirds ingesting marine plastics. Mar. Pollut. Bull. 69, 219-222.

Ter Halle A., Ladirat L., Martignac M., Mingotaud A.F., Boyron O., Perez E., 2017. To what extent are microplastics form the open ocean weathered? Environ. Pollut. 227, 167-174.

Teuten E.L., Saquing J.M., Knappe D.R.U., Barlaz M.A., Jonsson S., Björn A., Rowland S.J., Thompson R.C., Galloway T.S., Yamashita R., Ochi D., Watanuki Y., Moore C., Viet P.H., Tana T.S., Prudente M, Boonyatumanond R., Zakaria M.P, Akkhavong K., Ogata Y., Hirai H., Iwasa S., Mizukawa K., Hagino Y., Imamura A., Saha M., Takada H., 2009. Transport and 
release of chemicals from plastics to the environment and to wildlife. Philos. T. Roy. Soc. B $579364,2027-2045$.

580

581

582

583

584

585

586

587

588

589

590

591

592

593

594

595

596

597

598

Van Cauwenberghe I., Janssen C.R., 2014. Microplastics in bivalves cultured for human consumption. Environ. Pollut. 193, 65-70.

Van Sebille E., Wilcox C., Lebreton L., Maximenko N., Hardesty B.D., Franeker J.A., Eriksen M., Siegel D., Galgani F., Lavender Law1 K.L., 2015. A global inventory of small floating plastic debris. Environ. Res. Lett. 10, 1-11.

Wong-Wah-Chung P., Lebarillier S., 2017. Analysis of PAHs in marine plastics debris from North Atlantic gyre by UPLC and Fluorescence Detection, Application note Perkin Elmer.

Yamashita R., Takada H., Fukuwaka M.-A., Watanuki Y., 2011. Physical and chemical effects of ingested plastic debris on short-tailed shearwaters, Puffinus tenuirostris, in the North Pacific Ocean. Mar. Pollut. Bull. 2845-2849.

Zhang W., Mab X., Zhang Z., Wang Y., Wang J., Wang J., Mad D., 2015. Persistent organic pollutants carried on plastic resin pellets from two beaches in China. Mar. Pollut. Bull. 99, 2834. 